\title{
The relationships among impulsivity, anxiety sensitivity and nonsuicidal self-injury characteristics in patients with phobias
}

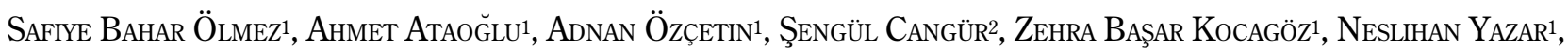 \\ BÜŞra BAHAR ATAOĞLU3
}

1 Department of Psychiatry, Duzce University School of Medicine, Duzce, Turkey.

2 Department of Biostatistics and Medical Informatics, Duzce University School of Medicine, Duzce, Turkey.

${ }^{3}$ Department of Clinical Psychology, Duzce University Health Sciences Institute, Duzce, Turkey.

This research was carried out in the Department of Psychiatry in Duzce University School of Medicine, 81620, Konuralp, Duzce-Turkey.

Received: 03/18/2018 - Accepted: 09/10/2018

DOI: 10.1590/0101-60830000000171

\begin{abstract}
Background: The relationship between impulsivity and nonsuicidal self-injury (NSSI) has been revealed in several mental disorders other than phobias. Objectives: The purpose of this study was to examine the relationships among impulsivity, anxiety sensitivity, and NSSI characteristics in patients with phobias, and to compare these relationships with healthy controls. Methods: The sample of this study consisted of outpatients ( $\mathrm{n}=109$ ) who had been diagnosed with social phobia, agoraphobia or simple phobia in addition to healthy individuals $(\mathrm{n}=51)$ serving as the control group. Data collection tools were the socio-demographic form, the Barratt Impulsivity Scale (BIS-11), the Inventory of Statements About Self-Injury (ISAS), and the Anxiety Sensitivity Index (ASI-3). Results: Mean BIS-11 and ASI-3 scores in the social phobia and agoraphobia groups were found to be significantly higher than those in the control group. In addition, a positive correlation was found between ISAS and cognitive anxiety sensitivity scores in the agoraphobia and simple phobia groups. Discussion: The study revealed a positive correlation between cognitive anxiety sensitivity and NSSI in both the agoraphobia and simple phobia groups. The results of this study indicate that anxiety sensitivity may play a regulatory role between impulsivity and NSSI in some sub-groups of phobia.
\end{abstract}

Ölmez SB et al. / Arch Clin Psychiatry. 2018;45(5):119-24

Keywords: Agoraphobia, anxiety sensitivity, impulsivity, nonsuicidal self-injury, phobia.

\section{Introduction}

The feeling of anxiety that is experienced in the face of a threat or a danger is defined as "fear". If the fear is excessive or irrational happening as a result of threatining objects or situations, then it is called as "phobia". Social phobia, agoraphobia and simple phobia, as types of phobias, are mental disorders within the category of anxiety disorders according to the fifth version of the Diagnostic and Statistical Manual of Mental Disorders of the American Psychiatric Association (DSM-5)2. DSM-5 suggested the name as "social anxiety disorder" for social phobia². However, the name of social phobia is still commonly preferred by psychiatrists. In this article, we preferred to use the name "social phobia" instead of "social anxiety disorder" for keeping content integrity with agoraphobia and simple phobia. Phobias have similar characteristics in terms of their etiological and epidemiological features, clinical signs, and association with other mental disorders ${ }^{1}$. One of the well-known characteristics of phobia patients is avoidance behaviors, which is a way to move away from the threating situation for phobia patients. Phobia patients use avoidance behaviors to stay safe and reduce their anxiety ${ }^{1}$.

Impulsivity includes behavioral patterns that are incompatible with the environment in place, applied to seek out excitement and pleasure, unplanned, and can lead to risky outcomes ${ }^{3}$. The accompaniment of impulsivity with any kind of mental disorder is known to make diagnosis and treatment more difficult than others which have not impulsivity component ${ }^{4}$. Although the relationship between impulsivity and anxiety has been generally considered to be contrary in past research, some recent studies have shown that impulsivity can also be observed in many anxiety disorders as well as influence the course of the disorder and the treatment process ${ }^{5,6}$. For instance, in a study by Del Carlo et al. ${ }^{6}$ examining the characteristics of impulsivity in patients with anxiety disorders. Del Carlo et al. found that impulsivity characteristics of patients with anxiety disorder such as panic disorder (with or without agoraphobia), generalized anxiety disorder, and social phobia, were significantly higher than the healthy controls. Thus, Del Carlo et al. claimed that impulsive behaviors could increase as a result of high stimulation caused by anxiety in these susceptible individuals with anxiety disorders 6 .

Nonsuicidal self-injury (NSSI) can be defined as self-harm actions of an individual which lead to disrupt tissue integrity without a suicide attempt ${ }^{7}$. Some recent studies have pointed out that NSSI can be observed with patients with anxiety disorders as an independent sign from comorbid personality disorders or depression ${ }^{8,9}$.

One of the most common clinical characteristics accompanying with NSSI is impulsivity, and there exists limited studies examining the relationship between impulsivity and NSSI in the category of anxiety disorders, in comparison to other mental disorders ${ }^{8-12}$. In a study by Chartrand et al., 5,910 patients with anxiety disorders were examined related their suicide attempts and NSSI, and then a comparison was made between suicide attempts and NSSI of these patients ${ }^{11}$. They found that both suicide attempts and NSSI are high in patients with several anxiety disorders ${ }^{11}$. Chartrand et al. also observed that patients with social phobia display a NSSI 2.27 times higher than those in healthy control group in their lifetime period ${ }^{11}$.

It has been known that individuals with high impulsivity often resort to NSSI in situations of conflict or stress ${ }^{8-12}$. In the case of phobia, individuals differ in their methods for coping with anxiety although "avoiding behavior" is usually expected to develop from the situation or object that constitutes the phobia. There might be several individual factors that can influence the methods of coping in the presence of both anxiety and impulsivity. Anxiety sensitivity is the state of excessive fear towards the symptoms of anxiety and its outcomes ${ }^{13}$. Our hypothesis was that anxiety sensitivity might be one of the characteristics that have a regulatory role among anxiety, impulsivity, and coping behaviors related to anxiety. Therefore, the purpose of this study was to investigate 
the relationships among impulsivity, NSSI, and anxiety sensitivity characteristics in patients with social phobia, agoraphobia or simple phobia, and to compare these relationships within phobia sub-groups and across healthy controls.

\section{Methods}

\section{Participants}

The sample of this study consisted of outpatients with social phobia $(\mathrm{n}=42)$, agoraphobia $(\mathrm{n}=27)$, and simple phobia $(\mathrm{n}=40)$ who applied to the psychiatry clinic of an university hospital for one year, in addition to healthy individuals $(n=51)$ who had not received any psychiatric diagnosis, serving as the control group. These individuals in the three phobia groups were selected from outpatients who had been diagnosed with only one of the phobias (social phobia, agoraphobia, and simple phobia), and those without other psychiatric comorbidities after a clinical interview based on DSM- 5 criteria $^{2}$. An appropriate permission (Decision number: 2015/73) was received from the Clinical Research Ethics Committee of the University on $14 / 12 / 2015$ for this study and informed consents were obtained from all of the participants by researchers.

\section{Instruments}

The data collection tools of this study were the socio-demographic form, and the Barratt Impulsivity Scale (BIS-11), and the Short Form of the Barratt Impulsivity Scale-11, the Inventory of Statements About Self-Injury (ISAS) and the Anxiety Sensitivity Inventory (ASI-3)14-16.

The BIS- 11 consists of 30 questions answered on the basis of self-report ${ }^{14}$. The BIS-11 has three subscales including attention impulsivity (cognitive irregularity and rapid decision making), motor impulsivity (impatience, sudden and unplanned mobility), and non-planning impulsivity (not making any plan due to focus on the present time). To evaluate the BIS-11, four different scores are obtained including total, non-planning, attention and motor impulsivity scores. The higher the total BIS-11 score mean the higher the impulsivity of the individual. The short form of the BIS-11 is a scale created by the same researchers in order to make the scale shorter and more practical, and it consists of 15 questions from the BIS- $11^{17}$. In this study, the brief form of the BIS- 11 was used to obtain the sub-scale scores because it provides more predictable results than the original BIS-11 in obtaining sub-scale scores in Turkish ${ }^{18,19}$. Validity and reliability of both scales' Turkish version (i.e., original BIS-11 and its brief form) were confirmed by Güleç et al.14,17-19.

The ISAS, developed by Klonsky and Glenn, is a two-part, selfreported measure. In the first part, whole life frequency of 12 types of NSSI is measured. In the second part, total interpersonal and intrapersonal function scores are obtained by summing the scores of each sub-function related to interpersonal and intrapersonal functions of NSSI ${ }^{19}$. Validity and reliability of the Turkish version of the scale was confirmed by Bildik et al.19,20.

ASI-3 is the latest version of the ASI, developed by Taylor et al. and the validity and reliability of the Turkish version of the scale was confirmed by Mantar et al. ${ }^{16,21}$. ASI-3 consists of 18 items based on self-report. The scale provides four scores including three separate sub-scores (physical, social and cognitive dimensions) and total ASI-3 scores ${ }^{16-21}$.

\section{Statistical analyses}

Statistical analyses were carried out in the SPSS (Version 18) program. While the assumption of normality was examined by the Shapiro Wilk test in continuous quantitative variables, homogeneity of variances was evaluated through the Levene test. For the continuous quantitative variables for which the assumptions hold, One-way ANOVA (post hoc Tukey test) was used to compare the groups in terms of socio-demographic characteristics and clinical scales. On the other hand, for variables for which the assumptions do not hold, Kruskal-Wallis (post hoc Dunn test) was used for group comparisons.

Additionally, Analysis of Covariance (post hoc Bonferroni and LSD tests) was conducted for comparisons among the groups by eliminating the effects of the confounding factors. In addition, Pearson and Spearman Correlation tests were applied to examine the relationships among quantitative variables. Relationships among categorical variables were also examined by the Pearson Chi-Square and FisherFreeman-Halton tests (post hoc Bonferroni adjustment method). In this study, $\mathrm{p}<0.05$ was considered as statistically significant.

\section{Results}

Socio-demographic characteristics of the groups

Table 1. Socio-demographic characteristics of the groups

\begin{tabular}{|c|c|c|c|c|c|c|}
\hline & & Social phobia $\mathrm{n}(\%)$ & Agoraphobia n (\%) & Simple phobia n (\%) & Control group n (\%) & $p$ \\
\hline \multirow[t]{2}{*}{ Genderf } & Male & $18(42.9)$ & $18(66.7)$ & $26(65.0)$ & $35(68.6)$ & \multirow[t]{2}{*}{0.054} \\
\hline & Female & $24(57.1)$ & $9(33.3)$ & $14(35.0)$ & $16(31.4)$ & \\
\hline \multirow[t]{2}{*}{ Marital status ${ }^{£}$} & Married & $8(19.0)_{a}$ & $23(85.2)_{b}$ & $25(62.5)_{b, c}$ & $23(45.1)_{c}$ & \multirow[t]{2}{*}{$<0.001$} \\
\hline & Single & $34(81.0)_{a}$ & $4(14.8)_{b}$ & $15(37.5)_{b, c}$ & $28(54.9)_{\mathrm{c}}$ & \\
\hline \multirow[t]{5}{*}{ Occupation\& } & Public servant & $4(9.5)_{a}$ & $1(3.7)_{a}$ & $7(17.5)_{a}$ & $12(23.5)_{a}$ & \multirow[t]{5}{*}{$<0.001$} \\
\hline & Worker & $4(9.5)_{a}$ & $4(14.8)_{a}$ & $10(25.0)_{a}$ & $10(19.6)_{a}$ & \\
\hline & Student & $26(61.9)_{a}$ & $2(7.4)_{b}$ & $6(15.0)_{b}$ & $24(47.1)_{a}$ & \\
\hline & Housewife & $2(4.8)_{a, b}$ & $13(48.1)_{c}$ & $9(22.5)_{b, c}$ & $2(3.9)_{a}$ & \\
\hline & Other* & $6(14.3)_{a}$ & $7(25.9)_{a}$ & $8(20.0)_{a}$ & $3(5.9)_{a}$ & \\
\hline \multirow[t]{2}{*}{ Residence\& } & Urban & 35 (83.3) & $21(77.8)$ & $36(90.0)$ & 49 (96.1) & \multirow[t]{2}{*}{0.058} \\
\hline & Rural & $7(16.7)$ & $6(22.2)$ & $4(10.0)$ & $2(3.9)$ & \\
\hline \multirow{3}{*}{$\begin{array}{l}\text { Monthly income } \\
\text { perception\& }\end{array}$} & Good & $7(16.7)$ & $3(11.1)$ & $2(5.0)$ & $2(3.9)$ & \multirow[t]{3}{*}{0.275} \\
\hline & Medium & $28(66.7)$ & $16(59.3)$ & 25 (62.5) & $35(68.6)$ & \\
\hline & Not Good & $7(16.7)$ & $8(29.6)$ & $13(32.5)$ & $14(27.5)$ & \\
\hline \multicolumn{2}{|l|}{ Age (years) $\alpha, \neq$} & $21.0(18-41)$ & 40.0 (18-55) & $33.5(18-65)$ & $26.0(19-65)$ & 0.001 \\
\hline \multicolumn{2}{|c|}{ Education level (years) $\alpha, *$} & $14.0(5-22)$ & $8.0(5-14)$ & $12.5(0-22)$ & $16.0(2-19)$ & 0.285 \\
\hline \multicolumn{2}{|c|}{ Mother education (years) $\alpha, \neq$} & $5.0(0-16)$ & $5.0(0-8)$ & $5.0(0-15)$ & $5.0(0-16)$ & 0.708 \\
\hline \multicolumn{2}{|c|}{ Father education (years) $\alpha, \neq$} & $8.0(0-18)$ & $5.0(0-11)$ & $5.0(0-16)$ & $11.0(0-16)$ & 0.090 \\
\hline \multicolumn{2}{|c|}{ Number of siblings $s^{\alpha, \sharp}$} & $3.0(1-7)$ & $4.0(2-10)$ & $3.0(1-8)$ & $3.0(0-12)$ & 0.700 \\
\hline
\end{tabular}

*: Unemployed, farmer, retired, worker, craftsmen; f: Pearson Chi-Square test (post hoc Bonferroni adjustment method); \&: Fisher-Freeman-Halton test (post hoc Bonferroni adjustment method): $\alpha$ : Kruskal-Wallis, $¥$ : Median (Minimum-Maximum). Each subscript letter denotes a subset of a group's categories whose column proportions do not differ significantly from each other at the 0.05 level. 
Table 1 presents the socio-demographic characteristics of the participants. Regarding age, the mean age in the social phobia group was found to be lower than the mean age in the other groups, and the mean age in the agoraphobia group was higher than the mean age in the other groups $(\mathrm{p}<0.001)$.

When the groups were examined according to the suicide attempts, only the individuals in the agoraphobia group were found to have a statistically significant higher suicide attempts than the control group $(\mathrm{p}=0.013)$.

\section{BIS characteristics of the groups}

Table 2 presents the BIS-11 scores of the groups. Regarding the impulsivity scores in Table 2, the mean total score of the BIS-11 (Mean \pm SD) was $59.9 \pm 9.0$ for the social phobia group, $59.8 \pm$ 8.6 for the agoraphobia group, $56.6 \pm 9.1$ for the simple phobia group, and $53.5 \pm 8.2$ for the control group when adjusted for age. This indicates that the total mean scores of the BIS-11 in the social phobia and agoraphobia groups were significantly higher than the total mean BIS-11 score of the control group ( $\mathrm{p}<0.001$ and $p=0.007$, respectively). There was no statistically significant difference among the groups in terms of motor impulsivity, attention impulsivity and non-planning impulsivity sub-scores $(\mathrm{p}=0.386, \mathrm{p}=0.493$ and $\mathrm{p}=0.400$, respectively) when adjusted for age.

\section{ASI characteristics of the groups}

Table 3 presents the total ASI- 3 scores and sub-scores of the groups. Based on Table 3, the total mean ASI-3 scores were found to be significantly higher in the social phobia, agoraphobia, and simple phobia groups than those in the control group ( $<<0.001, \mathrm{p}<0.001$ and $\mathrm{p}=0.019$, respectively) when adjusted for age.

Considering the ASI-3 sub-scores, the mean physical dimension scores in the groups of social phobia, agoraphobia, and simple phobia groups were significantly higher than those in the control group ( $\mathrm{p}<0.001, \mathrm{p}<0.001$ and $\mathrm{p}=0.015$, respectively) when adjusted for age. The mean physical dimensions score in the agoraphobia group were also significantly higher than those in the simple phobia group $(p=0.008)$. Moreover, when adjusted for age, the mean social dimensions score in the social phobia group were significantly higher than those in the other groups $(\mathrm{p}<0.001)$. Lastly, the mean cognitive dimension score in the social phobia group was significantly higher than same scores of the control and the simple phobia groups ( $\mathrm{p}<0.001$ and $\mathrm{p}<0.001$, respectively) when adjusted for age.

\section{ISAS characteristics of the groups}

Table 4 presents ISAS scores of the groups when adjusted for age. Considering the NSSI among the groups, there were 16 outpatients (16 out of 42) in the social phobia group, 7 outpatients ( 7 out of 29) in the agoraphobia group, 14 outpatients (14 out of 40 ) in the simple phobia group, and 6 healthy controls ( 6 out of 52) in the control group, who responded as "yes" to the screening questions in the first part of the ISAS, indicating the NSSI. While the most commonly

Table 2. Comparisons of BIS-11* scores and BIS-11* sub-scores in all groups

\begin{tabular}{|c|c|c|c|c|c|c|c|c|c|}
\hline & \multicolumn{2}{|c|}{ Social phobia $(n=42)$} & \multicolumn{2}{|c|}{ Agoraphobia $(n=27)$} & \multicolumn{2}{|c|}{ Simple phobia $(n=40)$} & \multicolumn{2}{|c|}{ Control group $(n=51)$} & \multirow[t]{2}{*}{$p$} \\
\hline & Mean \pm SD & M (Min-Max) & Mean \pm SD & M (Min-Max) & Mean \pm SD & M (Min-Max) & Mean \pm SD & M (Min-Max) & \\
\hline Motor Impulsivity*£ & $8.6 \pm 2.8$ & $9(3.0-16.0)$ & $8.3 \pm 2.8$ & $8(4.0-15.0)$ & $8.0 \pm 2.9$ & $7(4.0-18.0)$ & $7.6 \pm 2.3$ & $7(4.0-13.0)$ & 0.386 \\
\hline $\begin{array}{l}\text { Attentional } \\
\text { Impulsivity*E }\end{array}$ & $8.8 \pm 2.4$ & $9(5.0-14.0)$ & $8.5 \pm 2.2$ & $8(5.0-14.0)$ & $8.7 \pm 2.7$ & $8(5.0-17.0)$ & $8.2 \pm 2.4$ & $8(5.0-17.0)$ & 0.493 \\
\hline $\begin{array}{l}\text { Nonplanning } \\
\text { Impulsivity*£ }\end{array}$ & $10.4 \pm 2.3$ & $10(5.0-15.0)$ & $10.7 \pm 2.7$ & $11(7.0-16.0)$ & $9.9 \pm 2.8$ & $10(5.0-17.0)$ & $9.7 \pm 2.8$ & $10(5.0-19.0)$ & 0.400 \\
\hline Total Impulsivity*政 & $59.9 \pm 9.0$ & $60(42.0-80.0)$ & $59.8 \pm 8.6$ & $58(44.0-76.0)$ & $56.6 \pm 9.1$ & $55.5(40.0-84.0)$ & $53.5 \pm 8.2$ & $52(39.0-73.0)$ & 0.002 \\
\hline
\end{tabular}

SD: Standard Deviation; M (Min-Max): Median (Minimum-Maximum); : Analysis of Covariance; *:BIS-11 sub-scores which rated according to The BIS-11 brief form; **: BIS-11 Total Scores, significance at $p<0.05$.

Table 3. Comparisons of ASI- $3^{*}$ scores and ASI-3* sub-scores in all groups

\begin{tabular}{|c|c|c|c|c|c|c|c|c|c|}
\hline & \multicolumn{2}{|c|}{ Social phobia $(n=42)$} & \multicolumn{2}{|c|}{ Agoraphobia $(n=27)$} & \multicolumn{2}{|c|}{ Simple phobia $(n=40)$} & \multicolumn{2}{|c|}{ Control group $(n=51)$} & \multirow[t]{2}{*}{$\mathrm{p}$} \\
\hline & Mean \pm SD & M (Min-Max) & Mean \pm SD & M (Min-Max) & Mean \pm SD & M (Min-Max) & Mean \pm SD & M (Min-Max) & \\
\hline $\begin{array}{l}\text { Physical } \\
\text { concerns }\end{array}$ & $10.5 \pm 6.2$ & $10(0.0-22.0)$ & $13.1 \pm 6.3$ & $14(0.0-24.0)$ & $8.8 \pm 6.7$ & $7(0.0-22.0)$ & $5.1 \pm 5.6$ & $4(0.0-23.0)$ & $<0.001$ \\
\hline $\begin{array}{l}\text { Social } \\
\text { concerns**f }\end{array}$ & $15.5 \pm 5.1$ & $16.5(4.0-24.0)$ & $9.1 \pm 6.6$ & $8(0.0-21.0)$ & $8.3 \pm 4.8$ & $8(0.0-19.0)$ & $6.0 \pm 5.3$ & $5(80.0-20.0)$ & $<0.001$ \\
\hline $\begin{array}{l}\text { Cognitive } \\
\text { concerns }{ }^{* * \mathrm{f}}\end{array}$ & $10.2 \pm 5.8$ & $10.5(0.0-23.0)$ & $8.4 \pm 6.2$ & $8(0.0-21.0)$ & $5.9 \pm 4.9$ & $5.5(0.0-15.0)$ & $3.5 \pm 4.4$ & $2(0.0-20.0)$ & $<0.001$ \\
\hline $\begin{array}{l}\text { Total } \\
\text { ASI-3*Scoref }\end{array}$ & $36.2 \pm 13.8$ & $37(10.0-63.0)$ & $30.7 \pm 17.8$ & $30(1.0-65.0)$ & $23.3 \pm 13.8$ & $23(2.0-55.0)$ & $14.8 \pm 14.7$ & $9(0.0-69.0)$ & $<0.001$ \\
\hline
\end{tabular}

SD: Standard Deviation; M (Min-Max): Median (Minimum-Maximum); f: Analysis of Covariance; *: Anxiety Sensivity Index-3; **: Dimension Scores of the Anxiety Sensivity Index-3.

Table 4. Comparisons of ISAS* scores of individuals with NSSI** in all groups

\begin{tabular}{|l|c|c|c|c|c|c|c|c|c|}
\hline & \multicolumn{2}{|c|}{ Social phobia $(n=25)$} & \multicolumn{2}{c|}{ Agoraphobia $(n=15)$} & \multicolumn{2}{c|}{ Simple phobia $(n=25)$} & \multicolumn{2}{c|}{ Control group $(n=11)$} & $p$ \\
\cline { 2 - 10 } & Mean \pm SD & M(Min-Max) & Mean \pm SD & M (Min-Max) & Mean \pm SD & M (Min-Max) & Mean \pm SD & M (Min-Max) \\
\hline $\begin{array}{l}\text { Interpersonal } \\
\text { Functions Score\&f }\end{array}$ & $8.7 \pm 7.1$ & $7(0.0-20.0)$ & $4.0 \pm 1.1$ & $4(2.0-5.0)$ & $3.9 \pm 4.2$ & $3(0.0-13.0)$ & $6.5 \pm 6.6$ & $4.5(0.0-16.0)$ & $\mathbf{0 . 0 3 4}$ \\
\hline $\begin{array}{l}\text { Intrapersonal } \\
\text { Functions Score\&f }\end{array}$ & $8.8 \pm 5.9$ & $4(0.0-20.0)$ & $4.9 \pm 3.1$ & $4(2.0-9.0)$ & $4.2 \pm 2.7$ & $5(0.0-10.0)$ & $4.5 \pm 4.1$ & $3(0.0-11.0)$ & $\mathbf{0 . 0 3 0}$ \\
\hline Total Functions Scoref & $18.1 \pm 13.6$ & $18(1.0-44.0)$ & $8.9 \pm 3.9$ & $9(4.0-14.0)$ & $8.1 \pm 5.9$ & $7(1.0-19.0)$ & $11.0 \pm 10.4$ & $7.5(0.0-24.0)$ & $\mathbf{0 . 0 2 5}$ \\
\hline
\end{tabular}

SD: Standard Deviation; M (Min-Max): Median (Minimum-Maximum); f: Analysis of Covariance; *: Inventory of Statements About Self-Injury; ${ }^{* *}$ Nonsuicidal Self-injury, ${ }^{\&}$ Sub-scores of functios sections of ISAS. 
reported NSSI in each of the groups was "preventing wound healing", the other commonly reported characteristics were hair removal, biting and strike. An analysis of the NSSI of the participants in the four groups in terms of sub-functions related NSSI showed that all participants in four groups mostly used the NSSI to balance their affect regulation. Participants in four groups also used NSSI for distress labeling, revenge, and self-care. Furthermore, there were differences related to ISAS interpersonal and intrapersonal functions scores among the groups. Considering ISAS interpersonal and intrapersonal functions scores, the interpersonal functions scores in social phobia group were significantly higher than those in the agoraphobia and simple phobia groups $(\mathrm{p}=0.021$ and $\mathrm{p}=0.008)$ when adjusted for age. In terms of the intrapersonal functions scores in social phobia group, these scores were significantly higher than those in the agoraphobia and simple phobia groups $(\mathrm{p}=0.005$ and $\mathrm{p}=0.006$ ) when adjusted for age.

Table 5 presents the correlation between the anxiety sensitivity and the NSSI characteristics of the agoraphobia and simple phobia groups. Based on Table 5, there was a significant correlation between the cognitive dimension of ASI- 3 and intrapersonal and total function scores of the ISAS in the agoraphobia group's participants who reported the NSSI $(\mathrm{r}=0.845, \mathrm{p}=0.017$ and $\mathrm{r}=0.784, \mathrm{p}=0.037$, respectively). Likewise, a significant positive correlation was found between the cognitive dimension of ASI-3 scores and all ISAS scores of the participants in the simple phobia group who reported the NSSI. Lastly, there was also a significant positive correlation between the total ASI-3 score and the ISAS interpersonal function score in the simple phobia group $(\mathrm{r}=0.514, \mathrm{p}=0.050)$.

\section{Discussion}

The present study aimed to investigate the characteristics of impulsivity, anxiety sensitivity, and the NSSI of outpatients with social phobia, agoraphobia or a simple phobia, and to compare these characteristics within groups and healthy controls through self-reported scales.

Regarding age, the mean age in the social phobia group was found to be lower than the mean age in the other groups, and the mean age in the agoraphobia group was higher than the mean age in the other groups. Because significant difference was found among the groups in terms of age (median values), adjustments were performed by the Covariance analysis for all of the scales to adjust the age differences. The age differences among the groups were agreeable with the literature in terms of considering the most frequent age range of social phobia and agoraphobia and considering the age of application to the psychiatrist for treatment ${ }^{22-24}$. Previous studies in the literature have reported that simple phobia is a common emerging fear in early childhood, social fears in adolescence, and agoraphobia in early adulthood $22-24$. Additionally, patients with social phobia usually apply for treatment earlier than patients with agoraphobia as it is expected related most frequent age of disorders $22-24$.

In the present study, the impulsivity characteristics of patients with agoraphobia and social phobia were found to be significantly higher than those of the simple and control groups. Several studies in the literature have investigated the impulsivity characteristics of anxiety disorders ${ }^{6,25-30}$. Studies in the field of impulsivity characteristics of anxiety disorders have demonstrated that some of the patients with anxiety disorders have high impulsivity characteristics regardless of the additional symptoms of mood disorder or personality disorder6,25-30. In a study by Summerfeldt et al., the impulsivity characteristics of patients with various anxiety disorders were examined by administering the BIS-11 scale, and patients with social phobia and those with panic disorder (with or without agoraphobia) found to have a significantly higher BIS-11 total score and attention and non-planning sub-scores than other groups including healthy controls ${ }^{28}$. Summerfeldt et al.'s studies supported the findings of the present study for the social phobia and agoraphobia groups in terms of total BIS-11 score ${ }^{28}$. On the other hand, the present study found no significant differences among the groups in terms of sub-scores of BIS-11, which may be due to the presence of additional diagnoses of panic disorder in patients with agoraphobia in Summerfeldt et al.'s study ${ }^{28}$. Until the DSM-5, agoraphobia had not been considered as a separate diagnosis on its own but rather as a condition observed with panic disorder ${ }^{2}$. Hence, past research is limited to studies which have examined the impulsivity characteristics of patients with agoraphobia as part of panic disorder with agoraphobia $23,27,30,31$.

In terms of anxiety sensitivity, mean total ASI-3 scores in the social phobia, agoraphobia and simple phobia groups were significantly higher than those in the control group. In a study by Zinbarg et al. physical dimension scores of agoraphobia group was found to be significantly higher than in the simple phobia, social phobia, obsessive-compulsive disorder, and healthy controls groups ${ }^{32}$. Similarly, the results of the present study showed that physical dimension scores in the agoraphobia group and the social phobia group were significantly higher than those in the simple phobia group. The only difference between the study of Zinbarg et $a l$. and the present study is that in the present study, physical anxiety

Table 5. Correlations between ISAS* and $\mathrm{ASI}^{* *}$ scores in individuals with NSSI*** within the agoraphobia and the simple phobia groups

\begin{tabular}{|c|c|c|c|c|c|}
\hline & & & $\begin{array}{l}\text { Interpersonal Functions } \\
\text { Score }{ }^{\alpha}\end{array}$ & $\begin{array}{l}\text { Intrapersonal Functions } \\
\text { Score }{ }^{\alpha}\end{array}$ & Total Functions Score \\
\hline \multirow[t]{8}{*}{ Agoraphobia $(n=7)^{E}$} & \multirow[t]{2}{*}{ Physical concernsy } & $r$ & 0.226 & 0.687 & 0.616 \\
\hline & & $p$ & 0.626 & 0.088 & 0.141 \\
\hline & \multirow[t]{2}{*}{ Social concernsy } & $r$ & 0.450 & 0.638 & 0.642 \\
\hline & & $p$ & 0.312 & 0.123 & 0.120 \\
\hline & \multirow[t]{2}{*}{ Cognitive concernsy } & $r$ & 0.371 & 0.845 & 0.784 \\
\hline & & $p$ & 0.413 & 0.017 & 0.037 \\
\hline & \multirow[t]{2}{*}{ Total ASI-3 Score } & $r$ & 0.318 & 0.617 & 0.679 \\
\hline & & $p$ & 0.487 & 0.140 & 0.094 \\
\hline \multirow[t]{8}{*}{ Simple Phobia $(n=15) \& \&$} & \multirow[t]{2}{*}{ Physical concernsy } & $r$ & 0.153 & -0.221 & 0.008 \\
\hline & & $p$ & 0.587 & 0.429 & 0.977 \\
\hline & \multirow[t]{2}{*}{ Social concernsy } & $r$ & 0.383 & 0.270 & 0.394 \\
\hline & & $p$ & 0.159 & 0.331 & 0.146 \\
\hline & \multirow[t]{2}{*}{ Cognitive concernsy } & $r$ & 0.529 & 0.533 & 0.617 \\
\hline & & $p$ & 0.043 & 0.041 & 0.014 \\
\hline & \multirow[t]{2}{*}{ Total ASI-3 Score } & $r$ & 0.514 & 0.444 & 0.478 \\
\hline & & $p$ & 0.050 & 0.098 & 0.071 \\
\hline
\end{tabular}

f: Spearman Correlation test; \&: Pearson Correlation test, significant at $p<0.05 ;{ }^{*}$ : Inventory of Statements About Self-Injury; **: Anxiety Sensivity Index-3; ***: Nonsuicidal Self-injury; $\alpha$ : Sub-scores of functios sections of ISAS; $\gamma$ : Dimension Scores of Anxiety Sensivity Index-3. 
sensitivity scores of the social phobia group were similar to those in the agoraphobia group ${ }^{32}$. This difference might have resulted from the fact that the agoraphobia group in the study of Zinbarg et al. included patients with both agoraphobia and panic disorder ${ }^{32}$. Social dimension of anxiety sensitivity is a structural feature that may be used as a predictor for social phobia, as shown in the several metaanalyses ${ }^{33-37}$. Similarly, in the present study, we found that the mean social dimension score in the social phobia group was significantly higher than that in the other groups.

The mean cognitive dimension scores were found to be significantly higher both the social phobia and agoraphobia groups than those in the other groups ${ }^{34,38}$. Cognitive dimension of anxiety sensitivity in the agoraphobia group might be one of the cognitive signs of anxiety such as thoughts related loss of control. Similarly, with the patients with agoraphobia, patients with social phobia have some cognitive signs related their anxiety. Patients with social phobia also exaggerate their anxiety symptoms experienced during performance in social environments. Thus, their own assessments related their performance as much more worse than expected. These maladaptive thoughts also may be in an association with their high level of cognitive anxiety sensitivity.

It seems that the relationship between impulsivity and anxiety has a complex connection, which may be organized by many factors and leads different clinical features ${ }^{25,39}$. Although the nature of anxiety is considered to enable individuals to refrain from danger and to move away from the unplanned, sudden activities, current studies in the literature have pointed out that anxiety levels can influence impulsivity through some additional variables ${ }^{30,31,40}$. Anxiety sensitivity might be one of these variables that regulate the relationship between anxiety and impulsivity. In a study with a non-clinical sample consist of 508 adolescents, the associations of substance and alcohol use with impulsivity, anxiety and anxiety sensitivity were examined. The findings of this study showed that adolescents who has high level of anxiety and impulsivity as well as high anxiety sensitivity were found to use to more maladaptive ways of coping with stress such as substance and alcohol use ${ }^{41}$. Another maladaptive way of coping with anxiety might be NSSI and regardless of co-morbidity, NSSI and suicide attempts can also be observed at high rates in anxiety disorders ${ }^{42-46}$. The anxiety sensitivity might be a regulator between impulsivity and anxiety in the field of NSSI like as substance and alcohol using. Thus, regarding the relationship between anxiety sensitivity and NSSI in the present study, a significant positive correlation was found between cognitive dimension of anxiety sensitivity, and intrapersonal and total function score of the ISAS in both the agoraphobia and simple phobia groups. This indicates that the situation of sensitivity of cognitive symptoms of anxiety may be more related to NSSI than other dimensions of anxiety sensitivity. According to our review of the current literature, there exists only one study examining the relationship between the NSSI and anxiety sensitivity. The study which consists of 50 patients with post-traumatic stress disorder (PTSD) showed that higher anxiety sensitivity increased the symptoms of NSSI. Viana et al. also noted that the anxiety sensitivity could be used as a predictor of which of the traumatized individuals could develop NSSI ${ }^{47}$. Considering the results of this study along with our study, focusing on the psychotherapy applications towards cognitive dimension seems to be critical for preventing the NSSI both patients with PTSD and phobias.

The present study revealed that the participants in the agoraphobia group had significantly more suicide attempts than those on the control group $(p=0.013)$. In clinical samples where anxiety and impulsivity are both high, suicide is much more frequently observed than in clinical samples where anxiety and impulsivity are high separately ${ }^{48,49}$. Such a relationship can be considered to be regulated by anxiety sensitivity, similar to some other impulsive behaviors ${ }^{48,49}$. While the relationship between anxiety sensitivity and suicide has only been studied in a limited number of studies, one of these studies found that cognitive anxiety sensitivity was related to suicide attempts in patients with panic disorder ${ }^{48-52}$. Capron explains such a relationship by stating that, the catastrophic cognitions might be dominant in individuals with high cognitive dimension of anxiety sensitivity thus leads to attempt suicide than others who have anxiety in default of high cognitive anxiety sensivity ${ }^{51}$. When these individuals cannot cope with increased catastrophic cognitions, they can more often bring the idea of suicide into their cognitive-consciousness areas through with limbic-autonomic stimulation ${ }^{51}$. Considering cognitive dimension of anxiety sensitivity as representing sensitivity to fears such as loss of control, it can be a crucial factor for directing towards suicide rather than sensitivity to some somatic symptoms. In addition, we should keep in mind that the association of anxiety sensitivity with suicide and NSSI characteristics may also be regulated by other variables such as the ways of coping with stress, personality characteristics, and depressive symptoms. In the present study, we could not examine the relationship between suicide and anxiety sensitivity due to the limited number of patients reporting suicide attempts in the sub-groups, but the present study's findings are in line with the relevant literature in terms of the relationship between cognitive anxiety sensitivity and NSSI ${ }^{47}$.

Regarding limitations of the present study, one limitation is that the data collection tools are based on self-report, and this study contains a relatively small number of participants due to the fact that patients with phobia rarely apply to mental health professionals without having any other accompanying co-morbidity. In terms of generalizability of the findings reported in this study, future studies should use a larger sample size.

\section{Conclusions}

In conclusion, the findings of the present study highlight two important suggestions. First, some sub-groups of patients with social phobia or agoraphobia can display fewer avoidance behaviors than other patients with phobia, and they can exhibit several other impulsive behaviors such as NSSI in coping with their anxiety. Second, anxiety sensitivity in patients with anxiety disorder, especially in the presence of accompanying impulsivity characteristics might have a regulatory role regarding the methods that these patients will use for coping with their anxiety. Therefore, diagnosing individuals with higher cognitive anxiety sensitivity is critical for reducing both NSSI and other impulsive behaviors in patients with phobia.

\section{Disclosure statement}

No potential conflict of interest was reported by the authors.

\section{References}

1. Köroğlu E, Güleç C, Şenol S. Essential of psychiatry. 2th ed. In: Köroğlu E, Güleç C, editors. Social phobia and simple phobia. Ankara: Hekimler Yayın Birliği; 2007. p. 184-205.

2. American Psychiatric Association. Diagnostic and statistical manual of mental disorders. 5th ed. Arlington, VA: American Psychiatric Publishing; 2013.

3. Evenden J. Impulsivity: a discussion of clinical and experimental findings. J Psychopharmacol. 1999;13(2):180-92.

4. Sadock BJ, Sadock VA. Kaplan and Sadock's synopsis of psychiatry: Behavioral sciences/clinical psychiatry. Philadelphia: Lippincott Williams \& Wilkins; 2011.

5. Spinella M. Neurobehavioral correlates of impulsivity: evidence of prefrontal involvement. Int J Neurosci. 2004;114(1):95-104.

6. Del Carlo A, Benvenuti M, Fornaro M, Toni C, Rizzato S, Swann AC, et al. Different measures of impulsivity in patients with anxiety disorders: a case control study. Psychiatry Res. 2012;197(3):231-6.

7. Aksoy A, Ögel K. Self harm behaviors. Anadolu Psikiyatri Derg. 2003;4:226-36.

8. St Germain SA, Hooley JM. Direct and indirect forms of non-suicidal selfinjury: evidence for a distinction. Psychiatry Res. 2012;197(1-2):78-84.

9. Turner BJ, Dixon-Gordon KL, Austin SB, Rodriguez MA, Zachary Rosenthal M, Chapman AL. Non-suicidal self-injury with and without borderline personality disorder: differences in self-injury and diagnostic comorbidity. Psychiatry Res. 2015;230(1):28-35. 
10. Hawton K, Kingsbury S, Steinhardt K, James A, Fagg J. Repetition of deliberate self-harm by adolescents: the role of psychological factors. J Adolesc. 1999;22(3):369-78.

11. Chartrand H, Sareen J, Toews M, Bolton JM. Suicide attempts versus nonsuicidal self-injury among individuals with anxiety disorders in a nationally representative sample. Depress Anxiety. 2012;29(3):172-9.

12. Nock MK, Kessler RC. Prevalence of and risk factors for suicide attempts versus suicide gestures: analysis of the National Comorbidity Survey. J Abnorm Psychol. 2006;115(3):616-23.

13. Reiss S. Expectancy model of fear, anxiety, and panic. Clin Psychol Rev. 1991;11:141-53.

14. Patton JH, Stanford MS, Barratt ES. Factor structure of the Barratt impulsiveness scale. J Clin Psychol. 1995;51(6):768-74.

15. Klonsky ED, Glenn CR. Assessing the functions of non-suicidal selfinjury: psychometric properties of the Inventory of Statements About Self-injury (ISAS). J Psychopathol Behav Assess. 2009;31(3):215-9.

16. Taylor S, Zvolensky MJ, Cox BJ, Deacon B, Heimberg RG, Ledley DR, et al. Robust dimensions of anxiety sensitivity: development and initial validation of the Anxiety Sensitivity Index-3. Psychol Assess. 2007;19(2):176-88.

17. Steinberg L, Sharp C, Stanford MS, Tharp AT. New tricks for an old measure: the development of the Barratt Impulsiveness Scale-Brief (BISBrief). Psychol Assess. 2013;25(1):216-26.

18. Tamam L, Güleç H, Karataş G. Psychometric properties of the Turkish version of the Barratt Impulsiveness Scale-11 short form. Nöropsikiyatri Ars. 2013;50:130-4.

19. Güleç H, Tamam L, Güleç MY, Turhan M, Karakuş G, Zengin M, et al. Psychometric properties of the Turkish version of the Barratt Impulsiveness Scale-11. Klin Psikofarmakol B. 2008;18:251-8.

20. Bildik T, Somer O, Kabukçu Başay B, Başay Ö, Özbaran B. Psychometric properties of the Turkish version of the Inventory of Statements About Self-injury (ISAS). Turk Psikiyatri Derg. 2012;23:49-57.

21. Mantar A, Yemez B, Alkin T. Psychometric properties of the Turkish version of the Anxiety Sensivity Index-3. Turk Psikiyatri Derg. 2010;21:225-34.

22. Kessler RC, Petukhova M, Sampson NA, Zaslavsky AM, Wittchen HU. Twelve-month and lifetime prevalence and lifetime morbid risk of anxiety and mood disorders in the United States. Int J Methods Psychiatr Res. 2012;21(3):169-84.

23. Bandelow B, Michaelis S. Epidemiology of anxiety disorders in the $21 \mathrm{st}$ century. Dialogues Clin Neurosci. 2015;17(3):327-35.

24. Marks IM. Fears and phobias. Academic Press, 2013.

25. Nicholls J, Staiger PK, Williams JS, Richardson B, Kambouropoulos N. When social anxiety co-occurs with substance use: does an impulsive social anxiety subtype explain this unexpected relationship? Psychiatry Res. 2014;220(3):909-14.

26. Kashdan TB, McKnight PE. The darker side of social anxiety when aggressive impulsivity prevails over shy inhibition. Curr Dir Psychol Sci. 2010;19:47-50.

27. Jakuszkowiak-Wojten K, Gałuszko-Węgielnik M, Raczak A, Cubała WJ, Wiglusz MS, Herstowska M, et al. Impulsivity in panic disorder: neuropsychological correlates. Psychiatr Danub. 2013;25 Suppl 2:S149-52.

28. Summerfeldt LJ, Hood K, Antony MM, Richter MA, Swinson RP. Impulsivity in obsessive-compulsive disorder: comparisons with other anxiety disorders and within tic-related subgroups. Pers Individ Dif. 2004;36:539-53.

29. Barratt ES, Patton JH. Impulsivity: cognitive, behavioral, and psychophysiological correlates. Biological bases of sensation seeking, impulsivity, and anxiety. Hillsdale, NJ: Lawrence Erbaulum Ass; 1983.

30. Starčević V. Relationship between panic disorders, agoraphobia, and personality disturbance: An overview of research findings, and pertinent issues. Psihijatrija Danas. 1991;10-5.

31. Del Carlo A, Benvenuti M, Toni C, Dell'osso L, Perugi G. Impulsivity in patients with panic disorder-agoraphobia: the role of cyclothymia. Compr Psychiatry. 2013;54(7):1090-7.
32. Zinbarg RE, Brown TA, Barlow DH, Rapee RM. Anxiety sensitivity, panic, and depressed mood: a reanalysis teasing apart the contributions of the two levels in the hierarchial structure of the Anxiety Sensitivity Index. J Abnorm Psychol. 2001;110(3):372-7.

33. McWilliams LA, Stewart SH, MacPherson PS. Does the social concerns component of the anxiety sensitivity index belong to the domain of anxiety sensitivity or the domain of negative evaluation sensitivity? Behav Res Ther. 2000;38(10):985-92.

34. Rector NA, Szacun-Shimizu K, Leybman M. Anxiety sensitivity within the anxiety disorders: disorder-specific sensitivities and depression comorbidity. Behav Res Ther. 2007;45(8):1967-75.

35. Naragon-Gainey K. Meta-analysis of the relations of anxiety sensitivity to the depressive and anxiety disorders. Psychol Bull. 2010;136(1): 128-50.

36. Taylor S, Koch WJ, McNally RJ. How does anxiety sensitivity vary across the anxiety disorders? J Anxiety Disord. 1992;6:249-59.

37. Grant DM, Beck JG, Davila J. Does anxiety sensitivity predict symptoms of panic, depression, and social anxiety? Behav Res Ther. 2007;45:2247-55.

38. Deacon B, Abramowitz J. Anxiety sensitivity and its dimensions across the anxiety disorders. J Anxiety Disord. 2006;20(7):837-57.

39. Erwin BA, Heimberg RG, Schneier FR, Liebowitz MR. Anger experience and expression in social anxiety disorder: Pretreatment profile and predictors of attrition and response to cognitive-behavioral treatment. Behav Ther. 2003;34:331-50.

40. Gray JA. Perspectives on anxiety and impulsivity: A commentary. J Res Pers. 1987;21(4):493-509.

41. Comeau N, Stewart SH, Loba P. The relations of trait anxiety, anxiety sensitivity, and sensation seeking to adolescents' motivations for alcohol, cigarette, and marijuana use. Addict Behav. 2001;26(6):803-25.

42. Singhal A, Ross J, Seminog O, Hawton K, Goldacre MJ. Risk of self-harm and suicide in people with specific psychiatric and physical disorders: comparisons between disorders using English national record linkage. J R Soc Med. 2014;107(5):194-204.

43. Zetterqvist M. The DSM-5 diagnosis of nonsuicidal self-injury disorder: a review of the empirical literature. Child Adolesc Psychiatry Ment Health. 2015;9:31.

44. Hawton K, Kingsbury S, Steinhardt K, James A, Fagg J. Repetition of deliberate self-harm by adolescents: the role of psychological factors. J Adolesc. 1999;22(3):369-78.

45. Sareen J, Cox BJ, Afifi TO, de Graaf R, Asmundson GJ, ten Have M, et al. Anxiety disorders and risk for suicidal ideation and suicide attempts: a population-based longitudinal study of adults. Arch Gen Psychiatry. 2005;62(11):1249-57.

46. Schmidt NB, Woolaway-Bickel K, Bates M. Evaluating panic-specific factors in the relationship between suicide and panic disorder. Behav Res Ther. 2001;39(6):635-49.

47. Viana AG, Dixon LJ, Berenz EC, Espil FM. Trauma and deliberate self-harm among inpatient adolescents: the moderating role of anxiety sensitivity. Psychol Trauma. 2016;1:1-10.

48. Schmidt NB, Woolaway-Bickel K, Bates M. Evaluating panic-specific factors in the relationship between suicide andpanic disorder. Behav Res Ther. 2001;39:635-49.

49. Capron DW, Cougle JR, Ribeiro JD, Joiner TE, Schmidt NB. An interactive model of anxiety sensitivity relevant to suicide attempt history and future suicidal ideation. J Psychiatr Res. 2012;46(2):174-80.

50. Capron DW, Kotov R, Schmidt NB. A cross-cultural replication of an interactive model of anxiety sensitivity relevant to suicide. Psychiatry Res. 2013;205:74-7.

51. Capron DW, Fitch K, Medley A, Blagg C, Mallott M, Joiner T. Role of anxiety sensitivity subfactors in suicidal ideation and suicide attempt history. Depress Anxiety. 2012;29(3):195-201.

52. Allan NP, Capron DW, Raines AM, Schmidt NB. Unique relations among anxiety sensitivity factors and anxiety, depression, and suicidal ideation. J Anxiety Disord. 2014;28(2):266-75. 